\title{
Impacts of programmable manufacturing technology: A review of recent studies and contingency formulation
}

\author{
Jeffrey K. Likera , Ann Majchrzak ${ }^{\mathrm{b}}$ and Thomas Choi ${ }^{\mathrm{a}}$ \\ 'Industrial and Operations Engineering, University of Michigan, Ann Arbor, MI 48109, USA \\ ${ }^{b}$ Institute for Safety and Systems Management and Industrial and Systems Engineering, \\ University of Southern California, Los Angeles, CA 90089, USA
}

\begin{abstract}
This paper reviews the literature on the social impacts of programmable manufacturing technology (PMT). Several perspectives on the social impact of technology are identified ranging from simple additive models that view technology as having a set of individual and independent causal impacts to a contingency perspective which views the impact of technology as dependent on technical and organizational characteristics. The paper statistically summarizes 30 empirical studies within the 1986-1990 period and finds common trends in findings as well as contradictory evidence. The common trends are that PMT tends to lead to more organic organizations, but also meets with negative employee attitudes, stress, and perceptions of reduced job security and mobility. The contradictory evidence is that most studies report simple, additive effects, while a substantial portion find that the impacts depend on a wide range of contingency variables. The authors argue that simplistic views of PMT as being a homogeneous set of technologies with unidirectional, non-contingent social impacts is neither realistic nor useful. A number of future research directions in this area are suggested.
\end{abstract}

Keywords. Social impacts of technology; Programmable automation; CAD/CAM; Manufacturing; Sociotechnical systems; Organizational design

\section{Introduction}

The microelectronics revolution in manufacturing automation gives rise to varied images of its "social impact" depending on one's academic paradigm, political perspective, occupational position, and personal philosophy. To some, the impact is clearly favorable for the workforce and society-automation will not only help the bottom line, but also lead to jobs that are more enriched and

Correspondence to: Professor Jeffrey K. Liker, Industrial and Operations Engineering, University of Michigan, Ann Arbor, MI 48109, USA. 
challenging (Walton and Susman, 1987). Thus, the issue is to upgrade the skill levels of the workforce so they may take advantage, economically and personally, of the potential benefits offered by technology (Adler and Howard, 1990). To others, the computer revolution seems principally to be a threat to the job security of America's hourly workforce, particularly the unskilled. Jobs will be lost, those remaining degraded, and managers will have almost complete control of the workforce through sophisticated electronic monitoring in a kind of Orwellian nightmare (Baldry and Connolly, 1986; Gill, 1985; Cooley, 1981). A third view is that programmable automation has varied impacts, depending on such factors as management's foresight in redesigning jobs appropriately (Majchrzak, 1988; Adler, 1986), the existing skill level of the work force (Barley, 1986), characteristics of firms leading to "organizational inertia", (Dean and Snell, 1991), and political motivations of management and technology implementers (Shaiken, 1985; Thomas, 1993).

The first two views assume that technology has main effects only-there are certain predominate consequences for organizations adopting PMT (e.g., skill levels will be raised) with a few exceptions due to random variation. The third view assumes that technology has contingent impacts-consequences vary depending on a set of contextual factors. Note that a contingency model does not imply that on average PMT's positive and negative impacts of technology cancel out. For example, it is possible that companies primarily use PMT to achieve more flexible production and thus on average PMT has the effect of making organizations more organic, but depending on the product mix flexibility required by the market, manufacturing operations facing rapidly changing demand will shift to more highly organic forms than those with more stable, predictable demand. ${ }^{1}$

This paper reviews recent literature on the social impacts of programmable manufacturing technology (PMT). By this we mean programmable technology within manufacturing firms, on their shopfloor or in their offices. We were intentionally quite broad in our definition of PMT. The technology had to be based on a programmable computer system and installed in a manufacturing firm. We included within this broad definition programmable shopfloor automation such as numerically controlled machine tools and robots, computeraided design systems used in the engineering offices, manufacturing resource planning (MRPII) systems used for shopfloor control, and electronic data exchange technologies. In fact, when we searched for studies of such technologies in manufacturing environments, we ended up primarily with studies that included shopfloor automation like NC machines in their focus (80 percent)

\footnotetext{
${ }^{1}$ Burns and Stalker (1961) described environment-organization combinations that range from highly uncertain-organic to highly certain-mechanistic. Thus it is not inconsistent to assume one can find environments that vary in the degree of uncertainty and corresponding organizations vary in the degree to which they are organic.
} 
with a smaller proportion that looked at CAD or CAD/CAM systems (27 percent).

This paper has two purposes. First, we review recent empirical literature on social impacts of PMT to identify major trends in research findings, particularly with respect to evidence of main effects and contingent impacts. In particular, we statistically summarize empirical papers on the social impacts of PMT, published and unpublished, between 1986 and 1990. These papers focus principally on the impacts of technology internal to the firm, that is, microimplications for the organization and people in the firm. However, these internal impacts ultimatcly have societal impacts as well, such as when a company's upgrading of skill requirements for its workforce leads to a greater need for education from society. Second, we critically evaluate the existing literature and suggest future research directions.

\section{Importance of studying social impacts of PMT}

Why study the social impacts of PMT? There are at least three compelling reasons:

First, if the social impacts of technology are perceived as "harmful" by the workforce, the workforce is likely to resist the introduction of new technology. Resistance can take the form of employee turnover, absenteeism, and even sabotage through deliberate damage to equipment or unwillingness to contribute proactively to problem solving. For example, at Westinghouse a Fanuc robot was designed to user specifications but never used. A case study of the failed installation revealed the following sequence of events (Knight, 1985). A project team began design of the robot at the request of upper-level manufacturing managers. Shopfloor supervisors were not consulted during the design work. When the robot arrived, several technical problems needed to be worked out during production runs, but shopfloor personnel helped as little as possible and essentially circumvented the efforts of the project team staff. A study by the Congressional Office of Technology Assessment concluded: "The main stumbling blocks in the near future for implementation of programmable automation technology are not technical, but rather are barriers of cost, organization of the factory, availability of appropriate skills, and social effects of the technologies". (Office of Technology Assessment, 1984, p. 94; italics added).

A second reason is that part of planning the process of implementing new technology is the ability to anticipate and manage its "social impacts" (Bridges, 1991). Without awareness of these issues we are likely to continue to see technologies that are good ideas on paper remain on the shelf. The Manufacturing Studies Board of the National Research Council conducted a study of 24 cases of the implementation of CAM and CIM technologies and concluded: "Realizing the full benefits of these technologies will require systematic change in the management of people and machines, including planning, plant culture, 
plant organization, job design, compensation, selection and training, and labor-management relations" (Manufacturing Studies Board, 1986, p. 2).

A third reason takes a longer-term view. Studying the social impacts of programmable manufacturing technologies in micro-settings provides insights into broader historical social trends. It seems self-evident that the rapid introduction of micro-processors is contributing to fundamental changes in the workplace and the nature of work. Work in the 21st century is apt to be quite different from work in the 20th century. We are in a period of transition and studying the process of change is useful for historical documentation purposes as well as to help us predict and influence future societal trends.

\section{3. "Main effects only" models versus contingent social impacts}

The notion of uniform social impacts of technology typically implies a simple causal relationship: technology is implemented and a set of direct impacts follow. This view is sometimes referred to as the technological imperative perspective which "views technology as an exogenous force which determines or strongly constrains the behavior of individuals and organization" (Markus and Robey, 1988, p. 585).

In fact, there are strong theoretical reasons for believing that the predominant impacts of PMT will be to encourage more organic organizations characterized by broader, more flexible roles, greater multi-way communication, fewer rigid standard operating procedures, and the like. For example, building on the research stream launched by Joan Woodward's (1965) classic study of three types of manufacturing systems, researchers have recently provided evidence that there is a "fourth type"-high-technology batch production-which is based on the flexibility offered by programmable automation (Hull and Collins, 1987). In keeping with Woodward's technological imperative paradigm the suggestion is that, as we move to programmable automation, there is a particular best way to organize-in this case to more flexible, organic organizations. Programmable automation enables firms to economically make small lots of customized products reaping some of the cost advantages previously possible only in mass production systems and the flexibility of small-batch customized production. But to capitalize on this flexibility, firms must have flexible, i.e., organic, organizations. While it is possible for firms to use programmable automation strictly to automate mass-production single-product lines, they will get limited benefits from the programmability and may incur higher costs for the technology. The observation that effective use of PMT requires more organic organizations was strongly echoed in the NRC case studies, as summarized by Walton and Susman (1987). They argued, based on their observations of plants using PMT, that the most effective industrial plants that implemented programmable automation had "people policies" that em- 
phasize teamwork, training, employee involvement, flat management hierarchies, and the like.

Nonetheless, when we look at the various case studies of technological change in the literature, the technological deterministic perspective appears too simplistic to account for the varied effects of technology across cases (Majchrzak and Salzman, 1989; Crowston and Malone, 1988). For example, research on the effects of computerized technology on skill levels finds that skill upgrading or deskilling has less to do with the technology per se than it does with management discretion in designing jobs around the technology (Adler, 1986; Shaiken, 1985). It is preciscly this variation that would be expected and accounted for by a contingent-impacts perspective.

If we think about main effects in graphical form, plotting social impacts on the $Y$-axis and looking at the trend on the $X$-axis as we move from before PMT to after PMT we can think of three scenarios. What we will call in this paper a positive slope would mean a net upgrade in the jobs and quality of worklife. For example, if the "impact" of technology is to create more jobs, we would expect a positive slope from before PMT to after PMT. We would classify as a negative slope a scenario where the predominate consequence of PMT is to eliminate jobs. A finding of no main effects would be represented as a zero slope, e.g., the effect of PMT is no net gain or loss of jobs. Note that there will be variation around the central tendencies in each of these cases. For example, if the unit of analysis is the manufacturing plant, one might find that each plant has a different trend, but the average trend is either positive, negative, or no main effects.

The main-effects model can be represented by a simple additive model in which the implementation of technology is the independent variable and measures of social impacts are the dependent variables. Any variation not explained by the technology variable is represented either as systematic effects of control variables or random variation reflected in an error term. In the case of a finding of no main effects, one would conclude that PMT does not effect organizational variables. What is not considered under this model is that programmable automation might have systematically different consequences for subsets of the cases for the same social impact measure (e.g., some cases may experience raised skill levels while other cases may experience lowered skill).

As discussed earlier, equations for contingent impacts can take varying forms ranging from zero average effects to positive or negative average effects. One scenario is that under two different conditions the technology has different degrees of positive impacts. For example, Barley (1986) studied the same CT scanner technology introduced into two hospitals. In both cases, the traditional social distance between radiologists and lower-status radiological technicians was reduced, but it was reduced to a much greater degree in one hospital compared to the other. The difference seemed to be due to the initial skill levels of technicians-the traditional, hierarchical authority relationship was re- 
duced by the technology to a greater extent when technicians were already highly skilled radiologists prior to the introduction of the technology, as compared to when the technicians were relative novices.

A second case is when the impacts of the technology are negative under two conditions, but to a different degree. For example, two companies might cxperience job losses as a result of implementing PMT, but the percent of the workforce laid off could be lower in one plant that had relatively lean staffing to begin with. A third example is the most dramatic, showing mixed positive and negative slopes. In this case, the technology has a positive effect under one condition, but a negative effect under a second condition. For example, Shaiken (1985) observes cases in which programmable automation raises skill levels when NC programming is assigned to machinists and others where skill levels are reduced when NC programming is assigned to specialist programmers. He argues that this is the result of management discretion in designing jobs. What is interesting about the third example is that a pure main-effects model would find no impact of technology, whereas, by formulating the model based on the proper contingency formulation we find that there are positive impacts which on average cancel out negative impacts.

In this paper we will use the term "mixed impacts" to refer to findings that the impact of technology varies with some specifiable contingency variable. Thus, we would refer to all three of the examples given here as mixed-impact models.

A contingency model does not necessarily imply that technology has a mechanistic impact that will always vary in predictable ways under different circumstances such as the impact of a billiard ball under different gravitational forces. In fact, there would undoubtedly be individual cases that vary around each of the slopes. The goal is not to explain 100 percent of the variance. There is a danger in viewing technology as contingent on so many variables so that each and every case of technology introduction would be completely unique. In this case there would be no point in speaking of any systematic "impacts" of technology whatsoever.

Barley (1986) has attempted to reconcile interactionist perspectives on technology, which suggest highly particularistic impacts of technology, with structural perspectives, which assume systematic effects, through the use of Gidden's (1979) concept of structuration. Barley (1986) argues that technology presents "an occasion for structuring". Structure in this sense is viewed as a process rather than a static configuration; technology is viewed as having a reality which can bring about patterned social interaction. So, for example, when he observes that the introduction of CT scanners into radiology departments in two hospitals had similar effects on role relationships, but to different degrees, he argues that specific features of the technology brought about new patterns of role interaction, albeit to different degrees in different social contexts. As another example, Majchrzak (1991) views technology as delimiting 
organizational choices. Majchrzak (1991, p. 6) argues that "certain identifiable changes in organizational and human factors (such as tasks that need to be performed) can be directly attributable to technology". Based on an opensystems model she argues that certain organizational and job designs will fit with certain technology attributes, contingent upon the environment and strategic goals of management. This perspective does not assume that all managers will be aware of the need to change their organization to utilize the capabilities of new technologies, but that certain combinations of organization and technology will be more effective than others.

Majchrzak (1991) argues that technology does not cause organizational change, but rather particular features of technology delimit the range of effective organizational design choices in three different ways. The technology may require organizational changes for the technology to be used effectively (e.g., to prevent downtime), the technology may create new opportunities for organizational design such as new patterns of work (e.g., create opportunities for self-managing teams rather than purely sequential interdependence), and technology may eliminate certain design options (e.g., self-managing teams may become impossible when the technology creates sequentially interdependent work and workers are spaced far apart).

For example, one might imagine a scenario in which the use of CAD/CAM provides a stimulant to greater social interaction between product designers and manufacturing. Users of the technology quickly discover that in order to effectively prepare and translate the product data so they are useful for manufacturing purposes, design and manufacturing must arrive at a set of agreements and must communicate about the transfer of data. Thus, while implementors of the technology may not envision greater social interaction when they introduce the technology, to make the technology work may require such communication, in effect delimiting their social choices. In fact, Adler and Helleloid (1987) speculate, contrary to this hypothetical example, that effective CAD/CAM use requires social integration between design and manufacturing prior to implementation of the technology (ex ante), and attempts to use CAD/CAM to facilitate organizational integration (ex post) will be unsuccessful.

Open-systems theorists have long argued for a contingency perspective. For example, Nadler and Tushman (1980) argue that effective organizations must find a fit between their core tasks/technology, formal organizational arrangements, informal organization, employee characteristics, and the external environment of the firm. Socio-technical systems (STS) theory, which is based on open-systems theory, focuses particular attention on the social systemtechnical system fit (Burns and Stalker, 1961; Emery and Trist, 1978; Pasmore, 1988). They argue that joint optimization of the social and technical system will bring better results than optimizing either the social or technical system alone (Taylor and Asadorian, 1985). 
STS and organizational design theorists emphasize in particular the need for a fit between the external environment of the firm and the internal organizational design (Emery and Trist, 1965; Pasmore, 1988). For example, Burns and Stalker (1961) compared different industries whose environments ranged from highly stable to highly dynamic and found that more "organic" forms of organization were most effective when the environment is dynamic and more mechanistic organizations were most effective when the environment is stable. However, they have less to say about the social system characteristics which "fit" with different types of technology within the same industry facing a similar environment. A seminal formulation by Perrow (1967) suggests that when the technology is less routine (i.e., there are greater number of exceptions as hardware and software systems break down in unpredictable ways), more organic organization structures will be more effective, while more routine technologies fit with more mechanistic organizational designs. Despite the power of this formulation, there are clearly more ways to characterize technology and its context of use than technological uncertainty.

Like Majchrzak's (1991) formulation, the STS theorists seem to view technology as delimiting choices associated with organizational effectiveness. 'There is no law of nature driving managers to find the right fit between the technology and organization. In fact many seem to fail to understand the social system implications of technology (Majchrzak, 1988). Nonetheless, if a substantial number of managers understand the fit issue, one would expect to see patterned "impacts" of technology. However, the impact of technology will vary with a whole host of conditions that effect the fit between technology and organization (e.g., the external environment).

In sum, there appears to be general consensus in more recent theoretical formulations that assumptions of purely additive "impacts" of technology, as represented by main-effects models, are overly simplistic (Barley, 1986; Majchrzak, 1991; Kling and Scacchi, 1982; Markus and Robey, 1988). Yet, as we will see when we look at the existing literature, a surprising number of recent studies fail to even consider contingent relations.

\section{Research propositions}

We began with some a priori expectations about what the literature would reveal. We present these in the form of propositions to help frame the literature review. The first two propositions have to do with average trends across studies, i.e., main effects, while the second two are contingency propositions. We anticipated that there would be different average impacts of technology depending on whether we focused on organizational structure and processes or individual reactions. A summary of the social impact variables we examined is provided in Table 1.

Impacts on organizational structures and processes that we examined were 


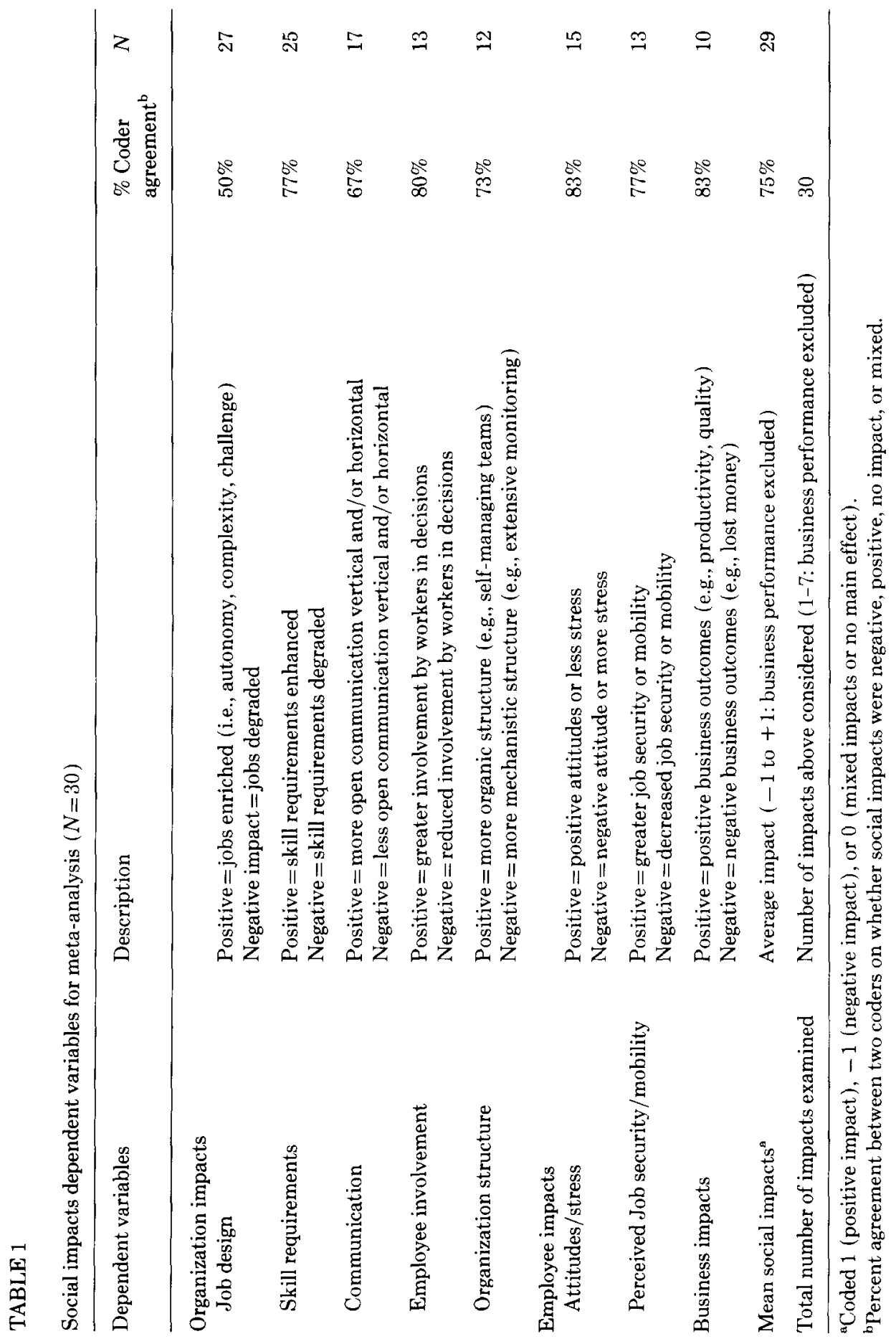


job and organizational design, skill requirements, communications, and employee involvement in decision making. The OTA report (1984) and National Research Council (NRC) studies (Manufacturing Studies Board, 1986) argue that new technology requires more organic organizational forms that include broader, more flexible job definitions, higher-level cognitive skill requirements, more open two-way communication across levels and across functions, and employee involvement in day-to-day decisions. This is also consistent with common STS interventions. While these interventions aim to achieve a fit between the environment, technical systems, and social systems, there is a remarkable consistency in the actual organizational solutions proposed. These solutions generally include the use of semi-autonomous work groups and an attempt to create an organic organizational environment (Emery and Trist, 1978; Pasmore, 1988; Taylor and Asadorian, 1985).

The basic argument is that programmable automation is effective at automating repetitive, manual tasks, but does not completely control itself. In part because the technologies are new and unproven, and in part because of their complexity, these technologies often fail in unpredictable ways. In Weick's (1990) terms, programmable manufacturing technologies are high on "equivoque". The result is that humans need to be an integral part of the deviation detection and correction loop. They need to monitor the technology, respond quickly to failures, and learn how the technology fails and ideally how to improve the technology. This requires initiative and autonomy that goes far beyond the repetitive, manual work characteristic of the age of scientific management. Thus, it is theorized that to effectively exploit PMT, organizations must be organic, providing workers with extensive training, timely and accurate information, autonomy, flexible jobs that allow workers to flexibly adapt to the situation, and involvement in technological improvement decisions. The proposition that derives from this is:

Proposition 1. Most studies will look only for main effects and report that programmable automation is associated with more organic organizations.

Given the prevailing reasoning about the impact of PMT, it should not be surprising that researchers will generally expect to find more organic organizations. However, why should they find that PMT is associated with more organic organizations? If, in fact, the world is such that a contingency model is a best fit, one might presume that researchers who fail to consider these contingencies will consistently find no effects of technology-positive and negative effects should cancel out. However, as discussed earlier, a contingency model does not mean that there are counterbalancing positive and negative effects. As examplified by Barley's (1986) study discussed earlier, it is possible to find that a technology leads to reduced social distance in general, but to 
different degrees under different conditions. Someone not recognizing the contingency would find a positive main effect which was the average of Barley's two different positive slopes. Moreover, a researcher may be capturing in their sample only a limited range on the contingency variable. For example, if the existence of a strong union prevented companies from laying off workers when they introduced PMT but researchers only studied non-unionized companies, they may find large numbers of jobs lost as a result of PMT despite the fact that, on average, across unionized and non-unionized companies the impacts are much less profound. As discussed in the next section, most of the studies of PMT impacts focused on quite small samples of manufacturing firms and often on a single plant so they were not likely to capture a range of the different cells in a contingency model.

If the organization adopting PMT, on average, becomes more organic and workers have more "enriched" jobs, does this mean workers will be happy? The answer is not necessarily affirmative. In a case study of the implementation of programmable automation in a small manufacturing firm, the first author and associates found general trends toward a more organic organization, but very mixed employee reactions depending on their position in the company (Liker et al., 1987). Employees who had jobs that were central to the functioning of the new programmable automation were generally enthusiastic about the new technology and the changes to their jobs. However, many long-time employees who worked on old equipment that was being phased out feared they would ultimately lose their jobs. Interestingly, employees selected to work with the new automation seemed excited but also reported more work-related stress than employees working on the old equipment. It seems that dealing with the project delays, uncertainty, and pressures of installing the new equipment led to long work hours and a stressful work environment. Thus, we see mixed results of the technology on individuals, depending on their work role, and some individuals had mixed reactions, enthusiasm tempered by stress. This leads to the second proposition:

Propositon 2. Individual reactions to programmable automation will be mixed, with neither positive nor negative reactions predominating.

The first two propositions focus on central tendencies, but we also expected considerable variation in the findings of studies. As discussed at the beginning of this article, one can find papers that report a very positive scenario of organic, open systems with enriched challenging jobs, those that report a negative scenario of degraded jobs and massive layoffs, and still others that identify mixed positive and negative results that can be explained by contingency variables that condition the impacts of technology.

We suspected that these differences in findings are partly attributable to the types of research methods used and the quality of the studies. For example, 
qualitative case studies might lead to different general findings than largesample surveys and peer-reviewed articles might have generally different findings than papers that have not undergone the scrutiny of the peer-review process. We attempted to develop specific propositions about the effects of various study characteristics, but this led to too many individual propositions to list here, as well as some contradictory propositions. For example, one can argue that qualitative case studies are more likely to lead to findings of contingent impacts as the researcher is confronted with all of the rich complexity of technology implementation, or one can argue that large-scale surveys are more likely to find contingent impacts as the larger sample provides more cross-site variation to analyze. Rather than attempt to precisely define the numerous possible propositions, we use the following summary proposition:

Proposition 3. The social impact of programmable automation varies systematically with the research method employed to study it.

We also expected that the theoretical framework of the researcher(s) would influence what they saw. In particular, we were interested in the difference between studies that reported main effects only and those that reported mixed impacts, e.g., varying slopes. We suspected that this depended on whether the author started out with a main-effects-only model or a contingency model as reflected in Proposition 4. That is, by failing to think in terms of contingencies, some authors will report only the average impact and interpret these as main effects. In this sense, what the researcher sees is influenced by what the researcher looks for.

Proposition 4. Researchers who propose a main-effects-only model will tend to report only main effects, whereas researchers who propose a contingency formulation will tend to report mixed impacts.

We turn now to the methods we used for identifying and classifying the thirty studies. We then present the study results which test our four propositions.

\section{Research design and measures}

\subsection{Selection of studies}

There already are reviews of social impact studies prior to 1986 (Majchrzak, 1988 ). Therefore, we focused our review on post-1986 studies. Based on database searches, conference proceedings, and personal contacts of the authors, we attempted to identify all studies of the social impacts of programmable automation in manufacturing that met the following conditions:

(1) empirical studies of actual organizations which implemented new pro- 
grammable automation (e.g., we excluded articles written from the experiences of managers who did not actually conduct a study of some kind);

(2) data collected in manufacturing sites, office or shopfloor;

(3) programmable automation as an independent variable;

(4) organizational or individual characteristics as dependent variables;

(5) all studies had proposed some impact of technology and empirically tested their hypotheses;

(6) papers written or published from 1986 to the time we collected the studies in 1990.

Based on these criteria we identified 30 separate studies (see Appendix for complete citations ). We cannot say whether we actually captured the universe of studies that met our criteria. However, we did not systematically omit any particular kinds of studies.

\subsection{Coding method}

Each study was summarized in several page documents by research assistants using a consistent format which described the technologies studied, independent variables, dependent variables, research methods used, a diagrammed version of the model presented or implied, and study findings. Based on these summaries, a final coding was performed. Two of the authors independently coded the studies and differences in coding were resolved through discussion and between the researchers. Interrater reliability was assessed as discussed in the next section.

\section{Coding social impacts}

All four propositions treat social impact measures as dependent variables. In Propositions 1 and 2 we consider the overall trends in the social impact findings and Propositions 3 and 4 focus on differences in findings across studies.

We first identified the social impacts to be examined and then coded the findings of the studies with respect to these social impacts. The categories of social impacts examined were determined inductively by identifying the most common impacts looked at in our sample of studies. For each variable, we then coded: (1) whether the studies examined the variable, and (2) whether they reported negative impacts, positive impacts, mixed positive and negative impacts, or no impact.

A summary of the social impacts we examined is provided in Table 1 . We distinguish in this table between impacts on organizational structures and processes (job design, skill requirements, communication, employee involvement, and organization structure) and impacts on individual reactive responses (attitudes/stress, perceptions of job security/mobility). Based on the most prevalent conception that programmable automation generally requires more organic organizational forms, we coded impacts as positive if the technology led 
to attributes associated with organic organizations, and negative if the technology led to more mechanistic characteristics (Burns and Stalker, 1961). For individual impacts, we assumed that job satisfaction and perceptions of job security/mobility were positive, while job stress, dissatisfaction and perceptions of job insecurity were negative. This is not to say that organic organizations are always better than mechanistic organizations or even that job stress is always bad. However, on average, if the predominate tendency of PMT was to lead to routine, unchallenging, stressful jobs, this would typically be viewed as a negative trend.

As can be seen in Table 1, the number of studies which examined each of the dependent variables varied. The large majority of studies considered impacts on job design and skill requirements ( 27 and 25 studies respectively), while only about one-third considered impacts on organizational structure, job security, and business impacts ( 12,13 , and 10 respectively). There were several social impacts that we wanted to investigatc but could not because of their almost complete absence from the studies examined. For example, reward structures were considered by only five studies and impacts on external relations with vendors and customers were considered in only two studies. We explain how we coded each of the social impact variables below, ordered from the most often examined impacts to the least often examined.

\section{Organizational impacts}

Job design. What happened to the jobs of individual workers? We considered changes in the job design dimensions in Hackman and Oldham's job diagnostic model (Hackman and Oldham, 1980) as well as more general statements of the challenge or boredom associated with the job. If jobs were enriched after the technology was implemented, we coded this as positive, whereas more routinized jobs were coded negative.

Skill requirements. Were there changes in the level of skill requirements with the new technology? This was defined in different ways across studies and we used the authors' definitions to code this variable. For example, if the authors concluded that skill levels were raised, we coded it that way. Generally if the workers had to learn new skills, such as computer programming, and used more cognitive skills as opposed to manual skills, this was coded as increased skill requirements.

Communication. Was there a change in the amount of communication, vertically or horizontally? If there was evidence that managers communicated more with their workers after the change or listened to their workers more, or evidence of more cross-functional communication, or more communication within 
a work group, we coded this as positive. If workers were more socially isolated after the change, we coded this as negative.

Employee involvement. Were there changes in the degree of employee involvement in decision making? If the change was accompanied by more employee participation in decisions about their job or work context, we coded this as positive. If employees were given less responsibility for decision making, we coded this as negative.

Organizational structure. Did the overall organization become more organically structured or mechanistically structured? For example, if the result was a flatter organization with loosely defined jobs and structures and flexible operating procedures, we coded this as positive. If more levels in the hierarchy were added, more rules were created, or the hierarchy was reinforced, we coded this as negative. Use of data for externally monitoring and controlling workers would also be coded negative as it is characteristic of a mechanistic organization.

\section{Employee impacts}

Employee attitudes/stress. What were people's attitudes toward the technology and accompanying changes? Did people say positive things about the technology or report a higher quality of work life when the new technology was introduced? Were they angry, threatened, dissatisfied?

Perceived job security/mobility. Did people perceive their job security or chances for job mobility as enhanced or diminished by PMT?

\section{Business impacts}

We looked at impacts on outcomes of the new technology on the functioning of the business. Were there increases or decreases in productivity, quality, sales, etc. as a result of the new technology?

In most cases the coding was straightforward as researchers used terminology similar to ours. For example, most studies explicitly considered the impact of the technology on job design using such terms as task complexity, vertical job loading, and job enrichment. We computed the percent agreement between the two independent coders as shown in Table 1 . On average, there was 75 percent agreement across the social impact measures. Agreement meant that we assigned the case to the same one of the four possible categories. Thus, by chance we would expect only 25 percent agreement. Differences in coding were resolved through discussion between the coders.

To test Proposition 3 we needed to code the social impact measures so they could be used as dependent variables. We tried three different approaches to 


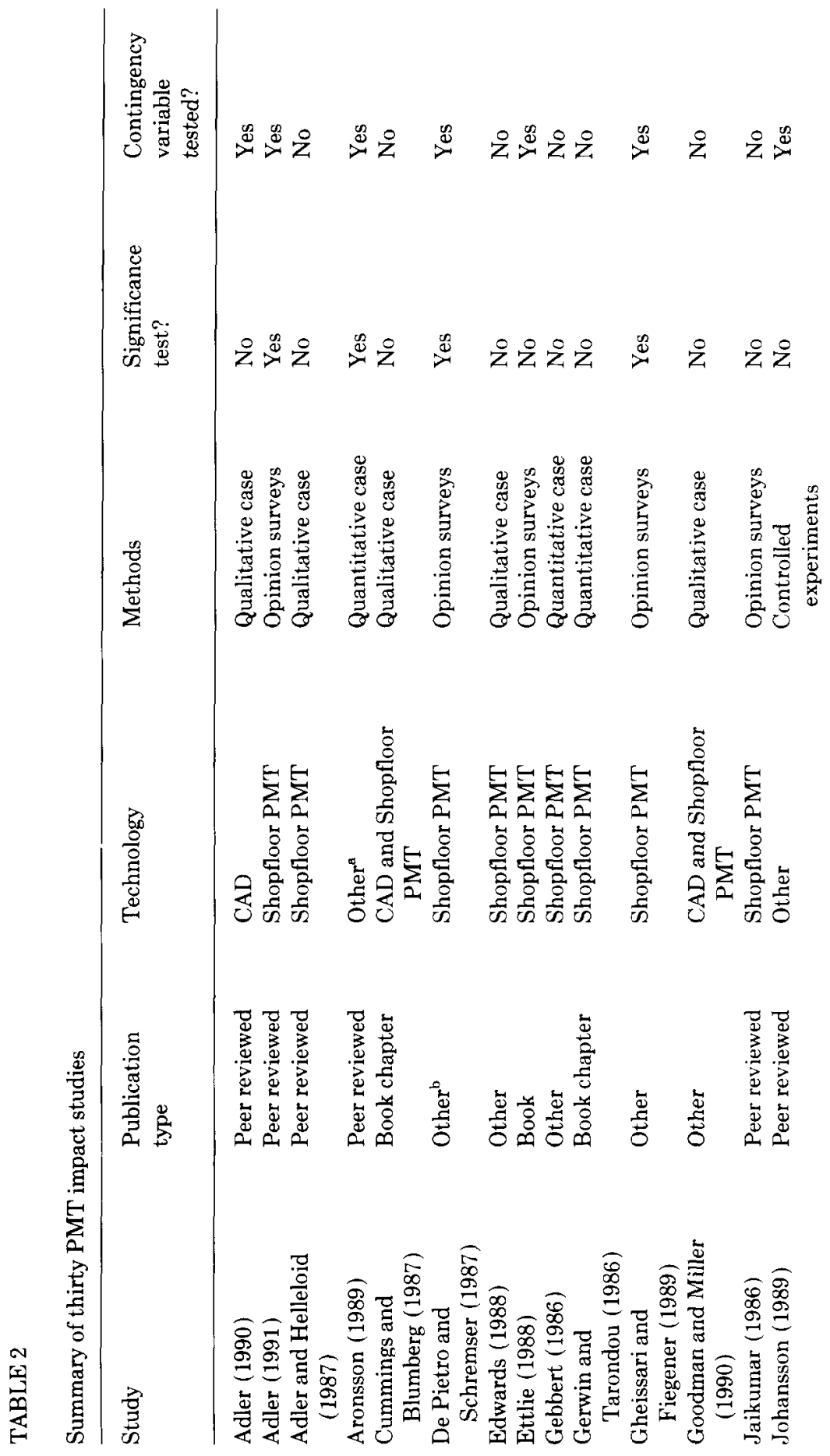




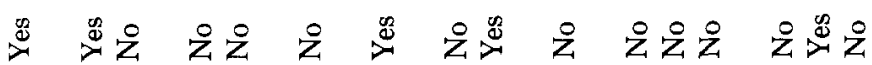

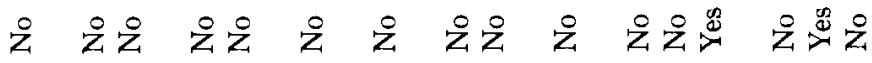

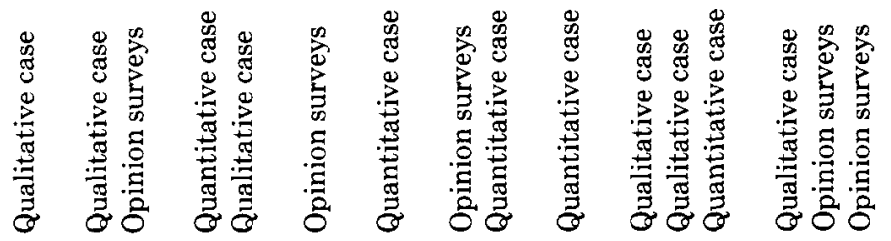

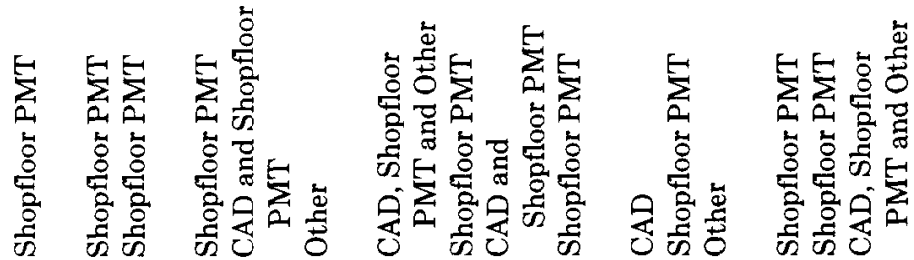

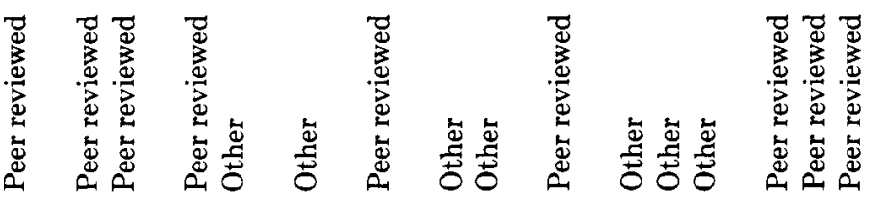

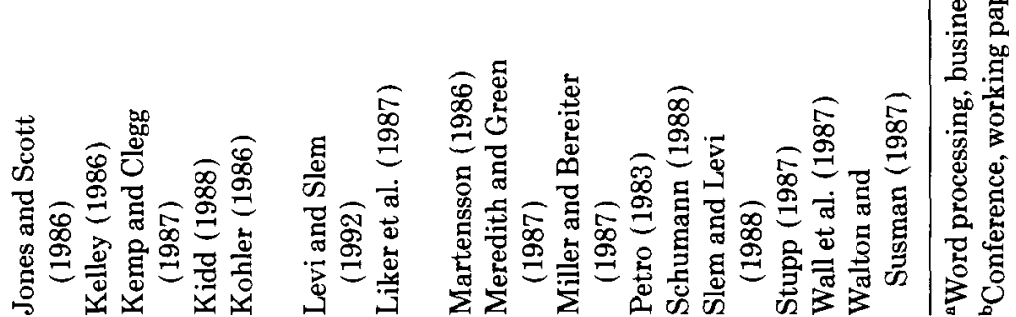


coding these dependent variables and ran all analyses with all three sets of measures. What varied was the way we handled findings of mixed impacts. First, we used the complete set of four categories-negative impacts, positive impacts, no impacts, and mixed impacts-and used chi-square statistics to assess the relationship between these social impact variables and study characteristics. Second, we combined findings of "no impacts" and "mixed impacts" into a single category scored zero so that the resulting variable was either positive impacts $(+1)$, negative impacts $(-1)$, or mixed/no impacts (0). Our rationale for combining mixed with no impact is that both findings seem less clearly positive than positive main effects and less clearly negative than negative main effects. One can certainly argue against this rationale, so we used a third method. The third approach treated mixed-impact studies as missing values and used a three-point scale of negative ( -1$)$, positive (1), and no impact $(0)$. We also computed the "average impact" for each study which was the average of all "social" impacts, excluding the business impacts. Finally, we looked at the number of impacts examined in each study.

To test Proposition 4 we needed to distinguish studies which reported main effects only from those which reported mixed impacts. We created a binary variable coding main effects only (positive, negative, or zero) as zero and mixed impact findings as one.

\subsection{Study characteristics}

In addition to social impacts, we recorded a number of study characteristics that can be viewed as moderator variables. That is, we asked whether the variation in observed relationships between technology and social impacts could be explained by these study characteristics. The thirty studies and how each were classified are presented in Table 2. Descriptive statistics summarizing the thirty studies are presented in Table 3 . We coded whether the study was published and if so whether this was in a peer-reviewed journal, the type of technology studied (shopfloor automation, computer-aided design (CAD), or other), which of four research methods were used, whether formal statistical tests were used, and whether any contingency variables were considered.

As shown in Table 3 only half of the studies we identified were in peerreviewed journals. The great majority of studies examined shopfloor automation ( 80 percent), most often some kind of numerically controlled (NC) machine tools, while 27 percent studied $\mathrm{CAD}$, and 20 percent examined other technologies, including manufacturing resource planning, order processing, and other database systems. These categories are not mutually exclusive-some studies investigated $\mathrm{CAD}$ and $\mathrm{NC}$ machines for example. It is interesting to note that two of the studies did not even describe any specific technology. They asked employees in a survey about their attitudes toward "new computer technology", as if all technologies were alike. 
TABLE 3

Independent variables for mela-analysis

\begin{tabular}{lll}
\hline Independent variables & Description & \\
\hline Published study? & Peer-reviewed journal & $53 \%$ \\
& Book/book chapter & $10 \%$ \\
& Other (e.g., conference, working papcr) & $37 \%$ \\
Technology & Shopfloor PMT & $80 \%$ \\
& CAD & $27 \%$ \\
& Other (e.g., word processing, business systems) & $20 \%$ \\
Research methods & Qualitative case studics & $37 \%$ \\
& Opinion surveys (multiple sites) & $33 \%$ \\
& Quantitative case studies (single sites) & $27 \%$ \\
& Controlled expcriments & $3 \%$ \\
Statistical tests & Significance test performed & $20 \%$ \\
Contingency variable considered & Model suggested contingent impacts & $40 \%$ \\
\hline
\end{tabular}

The research methods used in these social impact studies were based primarily on case studies, mainly qualitative (37 percent), with some single-site quantitative cases, typically retrospective (27 percent). Another 33 percent of the studies were based on larger-sample cross-sectional surveys. The one controlled experiment (Johansson, 1989) created a simulated situation to compare whether active or passive monitoring of the technology by workers was more stressful.

The majority of studies were based on a single site (24 percent) or 2-4 cases (48 percent) and even employee reactions were often based on interviews with a small number of people. Only 20 percent of the studies used any statistical tests of significance.

We coded whether the studies considered a contingency variable based on the theoretical models explicitly stated or implied in the papers. That is, we looked for some suggestion in the researchers' theoretical formulations that the impacts of technology might vary under different conditions. Only 40 percent of the studies made any mention of contingency variables-most studies assumed only main effects.

\subsection{Analysis methods}

To address Propositions 1 and 2, we examined the univariate distributions of "social impact" measures. We then examined bivariate relationships between each of the social impact measures and the study characteristics. As 
described earlier we tried three different coding methods for the social impact variables. We used chi-square statistics to test relationships with the fourcategory measures - positive, negative, zero, mixed. We used one-way ANOVA when we collapsed these into three ordinal categories-positive (1), negative $(-1)$, zero/mixed (0). Finally, we used chi-square statistics to examine the relationship between findings of main-effects-only versus mixed-impacts and the study characteristics.

We considered more complex analysis techniques. Salipante et al. (1982) suggest coding the actual effect size, but this was not possible in our case since we had a combination of qualitative and quantitative studies and most studies did not report formal measures of association. Multivariate analysis would also have been desirable. However, since most studies only examined a few of the social impact variables, the sample size for particular impacts was too low (e.g., nine cases for business impacts).

\section{Results}

\subsection{Overall distribution of social impact findings}

The overall distribution of findings for the 30 studies are presented in Table 4. As Proposition 1 predicts, among those studies that reported only main ef-

TABLE 4

Findings on social impacts of technology, 1986-1990

\begin{tabular}{|c|c|c|c|c|c|}
\hline \multirow[b]{2}{*}{ Social impacts } & \multirow[b]{2}{*}{$\begin{array}{l}\% \text { Considered } \\
\text { variable }\end{array}$} & \multicolumn{4}{|c|}{ Percent of those that examined variable finding } \\
\hline & & $\begin{array}{l}\text { Negative } \\
\text { main effect }\end{array}$ & $\begin{array}{l}\text { No main } \\
\text { effect }\end{array}$ & $\begin{array}{l}\text { Positive } \\
\text { main effect }\end{array}$ & $\begin{array}{l}\text { Mixed } \\
\text { impacts }^{\mathrm{a}}\end{array}$ \\
\hline \multicolumn{6}{|l|}{ Organization impacts } \\
\hline Job design & $90 \%$ & 7 & 7 & $\mathbf{5 5}$ & 30 \\
\hline Skill requirements & $83 \%$ & 4 & 4 & 63 & 29 \\
\hline Communication & $57 \%$ & 6 & 6 & 63 & 25 \\
\hline Employee involvement & $43 \%$ & 8 & 8 & 62 & 23 \\
\hline $\begin{array}{l}\text { Organizational } \\
\text { structure }\end{array}$ & $40 \%$ & 0 & 8 & 55 & 36 \\
\hline \multicolumn{6}{|l|}{ Employee impacts } \\
\hline Attitudes/stress & $50 \%$ & 33 & 0 & 13 & 53 \\
\hline Job security/mobility & $43 \%$ & 58 & 8 & 17 & 17 \\
\hline Business impacts & $33 \%$ & 0 & 0 & 67 & 33 \\
\hline
\end{tabular}

${ }^{a}$ Mixed impact means the study identified both positive and negative impacts for the particular variable (e.g., some increased skill level and some skill degradation). It does not necessarily mean the interaction effect was statistically tested. 
fects, the majority found positive impacts on organizational structure and processes. That is, as a result of implementing programmable automation, on average, jobs were more enriched, skill requirements were higher, communication channels were more open, employees were more involved in decision-making related to their jobs, and the overall organization was more organic. On average, across these five measures of organizational impacts, 60 percent of the studies reported positive impacts whereas only 5 percent reported negative impacts (with the remaining 29 percent of studies reporting mixed organizational impacts).

As Proposition 2 predicts, the impacts of the technology on individual attitudes/stress and job security/mobility were more mixed. However, we did not anticipate the preponderance of negative effects. For individual attitudes/stress, out of the 46 percent of studies that reported only main effects, 72 percent of these found negative impacts. On the other hand, in support of Proposition 2, the majority of studies found mixed impacts on attitudes/stress. For perceived job security/mobility, $70 \%$ of the studies that reported only main effects found negative effects. A smaller percent of studies (17 percent) found mixed results for this variable.

Finally, business impacts were studied in only 10 cases. Most studies reported positive effects (67 percent) and the rest reported mixed positive and negative effects.

\subsection{Social impacts related to study characteristics}

Since there was some variation in findings between studies, an interesting question is: What was the source of that variation? Why did some studies find positive impacts while others found negative impacts? Why did some studies report only main effects while others reported mixed impacts?

Proposition 3 suggested that social impact findings systematically varied with the research methods employed. To address this proposition, we first used the dependent variables as described in Table 1 and examined their bivariate relationship to each of the study characteristics in Table 2 using both ANOVA and contingency table approaches. Recall that three different formulations of the social impact variables were tried that treated the mixed impacts in different ways.

Despite all of the different bivariate relationships examined, the vast majority of these relationships were not significantly different from zero. That is, the proposition was not supported by the data. We tried the three different codings of dependent variables. We tried various ways of coding the independent variables. For example, we compared peer-reviewed publications to all others, then we compared peer-reviewed publications to book chapters to proceedings/unpublished papers. We compared shopfloor automation to all others, as well as shopfloor automation, to CAD only, to other technologies only. 
We compared qualitative studies to all others, surveys to all others, and case studies (qualitative/quantitative) to all others. The results were that very few coefficients were significant, even at a liberal 0.10 level.

There were a few exceptions where significance levels of 0.05 were achieved or nearly achieved. First, sample surveys compared to other methods predicted impacts on attitudes/stress $(p=0.01)$ and security/mobility impacts $(p=0.07)$. It seemed that surveys found positive impacts on employee attitudes (mean impact $=0.4$ ), whereas other methods (mostly case studies) showed negative impacts (mean impact $=-0.5$ ). Second, shopfloor automation compared to $\mathrm{CAD} /$ other technologies was associated with more positive attitudes on average (means $=0$ vs $-0.75 ; p=0.05$ ), and less perceived loss of job security/ mobility (means $=-0.1$ vs $-1.0 ; p=0.07$ ). Third, the use of formal significance tests compared to no statistical tests was associated with less positive effects on job design (means $=0$ vs $0.6 ; p=0.05$ ). Finally, peer-reviewed articles (versus others) was associated with less negative perceived job security/ mobility effects (means $=0$ vs $-0.83 ; p=0.06$ ).

Overall, these results suggest the impacts reported were quite robust with respect to the study methods, technologies, and publication outlet. There is a danger that the few exceptions where relationships were found resulted from Type 1 error. We ran many statistical tests and the sample size is quite small. For example, there were only ten cases that considered employment effects and thirteen cases that considered attitudes/stress. The independent variables were also highly skewed. For example, of the thirteen cases that looked at attitudes/stress, only three of these did not involve shopfloor automation. Therefore, contrary findings in even two non-shopfloor automation cases can have a serious impact on the observed relationship between type of technology and attitudes/stress.

\subsection{Mixed versus main-effects-only findings and study characteristics}

While most of the studies reported only main effects, a large minority reported mixed results. Thus, we compared mixed versus main-effect results for each social impact measure for each of the study characteristics in Table 2. The two study characteristics that were significantly related to mixed versus main effects were whether formal significance tests were reported and whether the study explicitly considered contingency variables.

Studies that used statistical tests were more likely to report mixed impacts. In all, 60 percent of the six studies that used statistical tests found mixed results on job design versus 19 percent of studies that did not use these tests $(p=0.06)$. Similarly, 60 percent of studies with significance tests found mixed impacts on skills compared to 21 percent of other studies $(p=0.08)$. The differences for other social impact measures were mixed and none was even near statistical significance. 
A more straightforward pattern of results is shown in Table 5. We looked at studies that considered contingency effects versus those where the theoretical model (explicit or implicit) assumed only main effects and found a strong relationship to findings of mixed versus main-effects-only results. In fact, researchers who did not consider contingency formulations in their model never reported mixed organization impacts.

This suggests that the research findings depended on the theoretical formulation. Researchers who looked for contingency variables reported contingent effects, whereas those who considered only main effects in their model found only main effects. One might argue that causality goes the other way. Researchers who found mixed results that they could tie to a contingency variable formulated a contingency model. The consequence is still that the result reported covaried with the theoretical model.

\subsection{Overview of contingent impacts}

We looked more closely at the twelve studies that considered contingent impacts and summarize their findings in Table 6 . What is most striking is that each of the twelve studies conceptualized the contingency variables in different ways and reached different conclusions about what matters. We were able to

\section{TABLE 5}

Percent of studies finding mixed impacts by whether contingency variables were considered in the model

\begin{tabular}{|c|c|c|c|c|}
\hline \multirow{2}{*}{$\begin{array}{l}\text { Dependent } \\
\text { variable }\end{array}$} & \multicolumn{2}{|c|}{ Percent found mixed results } & \multirow[t]{2}{*}{$p$-value ${ }^{a}$} & \multirow{2}{*}{$\begin{array}{l}\text { Number of } \\
\text { studies }\end{array}$} \\
\hline & $\begin{array}{l}\text { No contingency } \\
\text { variable in the } \\
\text { model }\end{array}$ & $\begin{array}{l}\text { Contingency } \\
\text { variable in the } \\
\text { model }\end{array}$ & & \\
\hline \multicolumn{5}{|l|}{ Mixed organization impacts } \\
\hline Job design & $0 \%$ & $73 \%$ & 0.0001 & 27 \\
\hline Skill requirements & $0 \%$ & $70 \%$ & 0.0002 & 25 \\
\hline Communication & $0 \%$ & $57 \%$ & 0.009 & 17 \\
\hline Employee involvement & $0 \%$ & $60 \%$ & 0.01 & 13 \\
\hline Organization structure & $0 \%$ & $67 \%$ & 0.02 & 12 \\
\hline \multicolumn{5}{|l|}{ Mixed employee impacts } \\
\hline Attitudes/stress & $33 \%$ & $83 \%$ & 0.06 & 15 \\
\hline Perceived job & & & & \\
\hline security/mobility & $13 \%$ & $25 \%$ & .58 & 13 \\
\hline Mixed business impacts & $33 \%$ & $33 \%$ & 1.0 & 10 \\
\hline
\end{tabular}

${ }^{a}$ Based on Chi-square tests. 


\section{TABLE 6}

Summary of contingent impacts identified ( 12 studies)

\begin{tabular}{|c|c|c|}
\hline Study & Contingency variable & Findings \\
\hline Gheissari and Fiegener (1989) & Worker skill level ${ }^{\mathbb{A}}$ & $\begin{array}{l}\text { Skilled workers (e.g., machinists, trades) had } \\
\text { higher skill levels/enriched jobs but unskilled } \\
\text { workers found jobs/skills degraded by new } \\
\text { technology. }\end{array}$ \\
\hline Liker et al. (1987) & $\begin{array}{l}\text { Structural position of } \\
\text { job }^{\mathbf{a}}\end{array}$ & $\begin{array}{l}\text { Workers whose jobs were automated reported } \\
\text { mostly positive changes, whereas those whose } \\
\text { jobs might be eliminated by new technology } \\
\text { reported mostly negative changes. }\end{array}$ \\
\hline Aronsson (1989) & $\begin{array}{l}\text { Hierarchical } \\
\text { occupational level }^{\mathrm{a}}\end{array}$ & $\begin{array}{l}\text { Low level = more stress, less social cohesion; } \\
\text { Middle level = more stress (but less than } \\
\text { lowest), no change in cohesion; Upper } \\
\text { level = no social impacts of computer } \\
\text { technology. }\end{array}$ \\
\hline
\end{tabular}

Kemp and Mueller (1987) Technology $\quad$ CNC implementation increased skill levels but automation that indicated with lights the position of work reduced skill levels.

Johansson (1989)

Adler (1990)

Product complexity ${ }^{b} \quad$ More complex products reinforce skill upgrading (espccially in design)

Production volume ${ }^{b} \quad$ Higher production volumes make downtime expensive and reinforce skill upgrading.

Kelley (1986)

Plant size, union, skill Small plants more skill upgrading than large base, management style ${ }^{c}$ plants, Union shops less skill upgrading (programming assigned to specialists) than non-union, history of skilled workers led to greater skill upgrading, scientific management philosophy led to skill downgrading whereas a participative management approach led to skill upgrading.

Martensson (1986)

Management approach Site 1 FMS = supervisor manages poorly and job design ${ }^{\mathrm{c}}$ leading to more mechanistic organization, less flexible workgroup, and production problems. 


\begin{tabular}{|c|c|c|}
\hline Study & Contingency variable & Findings \\
\hline & & $\begin{array}{l}\text { Site } 2 \text { FMS = autonomous work teams created, } \\
\text { more contact with environment, greater skill } \\
\text { levels, and smoother production. }\end{array}$ \\
\hline Adler (1991) & Organization design $^{c}$ & $\begin{array}{l}\text { Three FMS cases-Team design led to } \\
\text { upgrading of skills and intrinsic motivation } \\
\text { whereas "neo-traditional" organizational } \\
\text { design led to downgrading. }\end{array}$ \\
\hline Gerwin and Tarondea (1986) & $\begin{array}{l}\text { French versus American } \\
\text { plants-Management } \\
\text { Appruach }^{\circ}\end{array}$ & $\begin{array}{l}\text { American auto plants-shopfloor automation } \\
\text { reduced skill levels; French auto plants-same } \\
\text { technologies increased skill levels. }\end{array}$ \\
\hline Meredith and Green (1987) & Implementation process & $\begin{array}{l}\text { Poor implementation strategy increased } \\
\text { worker stress whereas skilful implementation } \\
\text { decreased worker stress. }\end{array}$ \\
\hline Jones and Scott (1986) & $\begin{array}{l}\text { Worker selection/Job } \\
\text { assignment }\end{array}$ & $\begin{array}{l}\text { American firm hired FMS workers from } \\
\text { outside and created an "FMS qualifier" job } \\
\text { leading to a flexible, highly skilled, } \\
\text { autonomous work group. British firm used } \\
\text { internal workers without FMS experience and } \\
\text { encouraged workers to select their own jobs, } \\
\text { leading to competition for jobs and guarding of } \\
\text { expertise with no net skill increase. }\end{array}$ \\
\hline
\end{tabular}

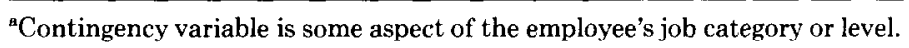

${ }^{b}$ Contingency variable is some characteristic of the task/technology.

${ }^{\text {C } C o n t i n g e n c y ~ v a r i a b l e ~ i s ~ s o m e ~ c h a r a c t e r i s t i c s ~ o f ~ t h e ~ o r g a n i z a t i o n a l ~ d e s i g n ~ o r ~ c u l t u r e . ~}$

identify five broad categories of contingency variables. The five categories of contingency variables are job categories of workers, technology characteristics, management philosophies and existing organizational designs, implementation process, and worker selection and job assignments. The studies by Gheissari and Fiegener (1989), Liker et al. (1987) and Aronsson (1989) all focused on the differential impact of technology on different job categories. Kemp and Mueller (1987), Johansson (1989), and Adler (1991) suggest that characteristics of the tasks or technology effect whether impacts are positive or negative. Kelley (1986), Martensson (1986), Adler (1991), and Gerwin and Tarondea (1986) all report that organization design and culture are key contingency variables. Meredith and Green (1987) suggest the implementation process will effect how workers are impacted, while Jones and Scott (1986) suggest how workers are selected and jobs assigned will influence outcomes, sometimes in unexpected ways. 


\section{Summary and discussion of findings}

To summarize our findings, we began by identifying 30 recent studies of the social impacts of programmable automation in manufacturing. These studies generally focused on shopfloor automation or CAD, relied on cross-sectional case studies or surveys with small numbers of plants, and rarely used tests of statistical significance or reported technology/business performance outcomes. Despite this, there was a striking amount of agreement on the average social impacts of PMT.

Beginning with the studies that reported main effects only, programmable automation generally seemed to be identified with more organic, open organizations with enriched jobs requiring higher skill levels. On the other hand, individual attitudes and perceptions of the impact of technology on job security/mobility were generally negative. In other words, the organization might become more open and participative with more interesting jobs, but individuals who feared for their jobs and their job mobility were likely to have negative feelings toward PMT (Liker et al., 1987). Even individuals who were not concerned about their jobs tended to experience greater job stress with the new, complex technology.

These average tendencies masked considerable variation in impacts. For those studies explicitly considering contingency variables, mixed results were often found. That is, the same technology had different effects depending on a whole host of factors. These factors included job categories of workers, technology characteristics, existing organizational design and culture, implementation process, and worker selection and job assignments.

These findings leave us asking several questions: (1) Does looking for only main effects limit findings to main effects? (2) Does looking for contingencies create contingencies? (3) Can the same social impact measure have main effects under some conditions and contingent effects under others, and if so does this itself imply contingent impacts? and (4) Is the variation in findings the result of the use of non-rigorous research methods evidenced in many of these studies?

On the last point, it is clear that these studies were based on weak research designs for testing causal propositions. Most of the studies stated findings as though they had proven a cause-effect relationship despite the fact that they were typically based on cross-sectional data, generally reported retrospectively. At best these studies provide evidence of association, not causation.

To provide an overall framework which captures the range of contingency variables identified in these studies, we developed Fig. 1. This systems model suggests that the "social impacts" of technology will vary depending on the state of the organization and its environment at the time $\left(T_{i}\right)$ the technology is introduced. The impacts depend on characteristics of the workforce (e.g., their skill levels, work roles, opportunities for employment outside their cur- 


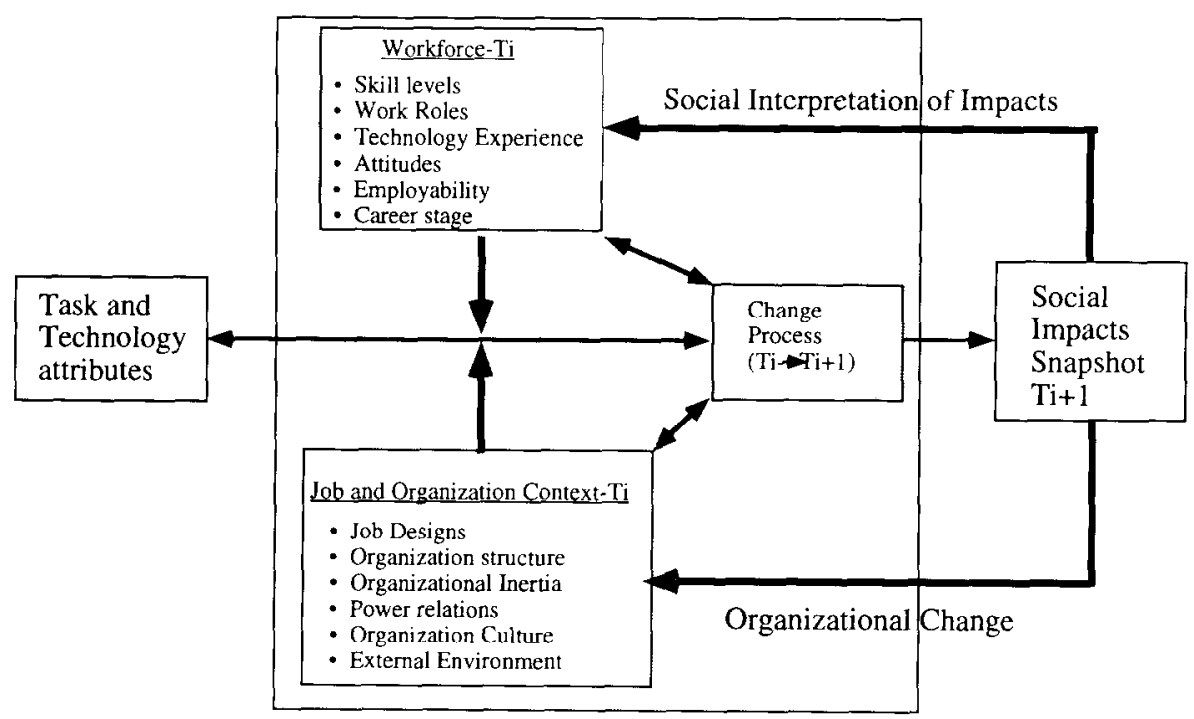

Fig. 1. Contingency model of social impacts.

rent job, attitudes toward technology, career stage, etc.) and the broader job and organizational context. This broader context includes the local context inside the firm, formal job and organizational designs and informal organizational characteristics (e.g., power relationships, leadership skills, culture), as well as characteristics of the broader environment (e.g., degree of uncertainty, job markets, competition, etc.). Up to this point the model is similar to Nadler and Tushman's (1980) version of the open-systems model. We add to this that the impacts of technology depend on the change process used to implement the technology and associated organizational changes (from $T_{i}$ to $T_{i+1}$ ).

Taken together, the technological and organizational changes lead to a new organizational state. At time $T_{i+1}$ one can take a "snapshot" of the organization and see certain "impacts". However, our model goes beyond the studies examined in assuming that the impact of technology is time-dependent. The state of the organization we will see depends on when we look. For example, early in the transition process we may see one set of impacts, and very different impacts at a later stage. To further complicate the model, members of the system are also aware of organizational changes and depending on how they interpret these changes (e.g., as a threat or opportunity), this will effect subsequent attitudes and actions. Moreover, the new organizational state now becomes the current context shaping future technological and organizational changes. Leonard-Barton and Sinha (1991) carry this dynamic view one step farther arguing that what really occurs is a "mutual adjustment" of technology and organization. They emphasize a two-way causal process in which organizations adapt to technologies but also adapt technologies to their needs. Thus, 
technologies are not an external force impacting the system, but the system also shapes the role and uses of the technologies as represented by the doubleheaded arrow from the change process back to task and technology attributes.

In sum, this model argues that technological change is a dynamic socio-technical process in which the "impacts" of technology depend on a number of contextual factors and will vary over time. This model seems to represent about the best we can say from existing literature which presents a confusing array of contingency variables. A major weakness of this model is that it suggests that everything is dependent on everything else and does little to prioritize the most important contingency variables that effect the influence of PMT. We will return to this point when we discuss future research needs.

\section{Critique of current literature}

Having gone through a rather detailed analysis of studies of social impacts of programmable automation in manufacturing, we found the results contradictory and of limited usefulness for management decisions. Two major reasons for this are:

First, these studies generally focus on description rather than explanation. They are simply a listing of observations; thus they are not really theory. Research on job design impacts does not explain what jobs mean to people, how the jobs get redefined, how these redefinitions create different skill needs, and how different skill needs create individual reactive responses. Discussions of implementation as a contingency variable does not explain the dynamic processes involved in worker participation and which aspects of that process are likely to yield the greatest worker gains. Moreover, the implementation processes described do not consider the dynamic readoption and reinvention activities involved in PMT implementation, the "mutual adaptation" discussed by Leonard-Barton and Sinha (1991).

Second, these studies are too simplistic and general. They often assume that one key variable, such as job skills, is the critical lever. They rarely consider social impacts of technology as the dynamic process depicted in Fig. 1 rather than as a static snapshot. They conceptualize technology as a simplistic single independent variable, e.g., CAD and NC machines are both simply programmable technologies.

We believe the study of the impacts of programmable manufacturing technology can neither be treated descriptively, simplistically, or generally. Instead, it must be treated as part of theory-building with complex contingency relationships. In our view, an appropriate treatment should have five key features: 
(1) PMT is similar to any major innovation in that it is likely to alter the organization in some way. In fact, describing PMT by Rogers' (1983) five attributes of innovations indicates that PMT as an innovation is likely to be very difficult to implement without major organizational adaptation: PMT is likely to be largely incompatible with existing systems, complex, not easily triable, results not often quickly observable, and of sometimes questionable relative advantage. Thus, building a theory of the impacts of technology should analyze the innovation itself as a phenomenon tightly interwoven with its impacts.

(2) PMT impacts relationships among variables, not just variables themselves. Most researchers look for impacts of technological change one-by-one on a set of organizational and individual characteristics, such as the skills needed, the job designs, the reward structure, and employee attitudes. We propose that this is the wrong place to look. Instead, we believe that PMT impacts the organization because it challenges and upsets current relationships: relationships among structural features of the organization, relationships among people, relationships between people and their jobs, relationships between the design process and people's role in that process. For example, significant work has attempted to assess the skill levels of workers with PMT; we believe it is not skill levels per se that should be the focus, but rather the relationship between the worker and the technology. Skill levels are simple by-products of these more fundamental changes, not the focus of the change itself.

(3) No accepted typology of PMT exists. Most of the literature on the impacts of PMT treats PMT (or its subcomponents such as CAD or CAM) as a unitary construct. The reality, of course, is that PMT is composed of a large array of systems, tools, product lines, between-system relationships, and production variances. While we can point to a broad set of characteristics which include programmability and use in manufacturing sites as we have done here, some PMT systems perform only a few computer-aided operations on a single product family and then the finished part is moved by a rigid transfer line to the next PMT system. Alternatively a PMT system may perform a series of computer-aided operations in a flexible sequence among a flexible set of other systems on a flexible set of parts. Clearly, the latter type of PMT system is far more complex. Differences among PMT systems are rarely described in sufficient detail, we believe, because there is no accepted typology for PMT. The organizational design literature characterizes technology in ways that are too abstract: a number of critically different PMT systems would all fall within categories marked: batch, reciprocally interdependent, nonroutine, or high task variety. 
(4) PMT impacts multiple organizational levels as well as alters levels of analysis. Traditional work design research has focused on the individual level of analysis. When traditional technology in a traditionally managed organization is brought in (such as a transfer line in a mechanistic stamping plant), studying the impacts on individual's attitudes and performance makes sense. When PMT is introduced, the changes to relationships often force an analysis of the impacts on and role of management, support functions, work units, as well as individuals. In addition, and perhaps more complicated, PMT often sufficiently alters the nature of the work such that subdivisions in work that were feasible previously (e.g., subdividing quality inspection work from part transformation work ) are no longer feasible. This means that often larger groupings of work must be considered, with this larger grouping no longer easily corresponding to what a single individual can do. Thus, PMT often poses the challenge of understanding the characteristics of work independent of what any one individual might do. Since this seems to be difficult conceptually for many social science researchers to understand, they often make the leap that PMT's impacts on jobs can be simply construed as a change in work design from an individual level to a work group level. However, not all work should necessarily be viewed as what individuals or groups do, but rather how tasks are grouped; who performs the task is a critical but separate issue. Thus, the introduction of PMT must be understood as altering the level of analysis for characterizing work.

(5) The role of systems theory must be applied, not simply recognized. Most researchers of PMT today appropriately reference early sociotechnical systems theory work as well as general systems theory for providing a philosophical orientation in which technology and social systems are viewed as complementary and congruent, and an understanding of boundaries, resource control, and human involvement is key to successful organizational functioning. Unfortunately, despite this recognition and referencing, most of the empirical studies seem content with simply recognizing and referencing their roots rather than clarifying and furthering the meaning and interrelationships of such vague constructs as equifinality, congruence, and complementarity. For example, some of the studies in our sample concluded that the ability of the organization to achieve positive benefits from PMT is contingent on the organizational context in which the PMT is implemented, i.e., the systems' notion that everything is dependent on everything else. Such a conclusion adds little to our ability to clarify how managers need to achieve congruence, equifinality, and complementarity when PMT is implemented. While Corbett's (1985) study might be an exception, there seems an unfortunate dearth in setting forth propositions that not only directly result from this system's tradition, but improve upon it. 


\section{Implications for future research}

There are a number of gaps in the available research literature-methodological, substantive, and theoretical. One of the most obvious implications that fall out of this review of recent research on the social impacts of programmable automation in manufacturing is that we need more methodologically rigorous research, particularly in some of the neglected areas. For example, more research is needed on the impacts of information and communication technologies in manufacturing. Production hardware such as robotics or NC machines are more traditionally associated with manufacturing, but there is an increasing investment in shopfloor controllers, information and communication technologies, automated scheduling systems, e-mail, various kinds of database systems, and shopfloor artificial intelligence (AI) systems. More research is also needed on the impacts of technology across organizational boundaries. As we move toward attempts to electronically link manufacturers with their suppliers and customers through CAD-to-CAD transfer of designs, computer networks, shared databases, and even fax machines, one would expect changes in the nature of communication across boundaries. Changes in reward systems that are appropriate for PMT and accompanying organization and job design changes need to be investigated. Research studies should also measure technological performance and business outcomes so that we can understand whether particular social impacts are related to performance. For example, are the resulting reductions in feelings of job security damaging to business performance?

While improving on current methods and adding additional technologies and organizational variables to the scope of programmable manufacturing technology would be useful, it is an incremental change to what has already been done. We believe there are five fundamental challenges for researchers in this field:

(1) We need characterizations of the PMT work environment that abstractly (but not too) describe the most critical features of PMT and PMT-related work. In the work of the second author on a characterization of technology design decisions for manufacturing, a several-hundred variable classification scheme was first developed; this scheme included such variables as reliability of the scheduling system, integration of the scheduling system with the operational equipment, and automaticity of the quality inspection system. This scheme, in fact, focused only on one class of PMT, flexible manufacturing cells. When it became clear that this level of technical specificity was too complex and too specific to one type of technology, we moved up a level to a smaller, more abstract set of concepts that pertain to how work is accomplished, regardless of the name of the technical system. As one example, the concept of reciprocal interdependencies among tasks, among technologies, among technologies and 
people, and among resources has become a critical one for understanding the impacts of PMT on human infrastructure design decisions. When the introduction of PMT modifies any of these interdependencies (such as in the case of introducing an automated parts tracking system), often the impact of PMT on how jobs should be designed is profound.

(2) Similarly, we need characterizations of organizational features that capture critical dimensions that interact with PMT. Models like Fig. 1 provide a starting point but suggest there is an almost limitless number of variables involved. Broad terms like "organic" versus "mechanistic" organizations do not capture the range of organizational forms that influence the impact of technologies and how they are adapted by the organization. We need middle-range characterizations between highly generic characterizations and highly specific characterizations of particular cases. We need ways of assessing where the organization is prior to implementation of technology so that we can understand how that shapes the subsequent "impacts" of technology.

(3) Studies of technologies impact should perhaps more appropriately be viewed as studies of the process of technological change. The theoretical focuses of our set of studies may portend of a broader classification: characteristics descriptive of the current work environment (i.e., formal organizational design features) and characteristics descriptive of how change in that work environment comes about (i.e., process features). With regard to the process of change, a set of characteristics must also be developed to include, for example, how users participate, the time line for implementation, readiness to change, and degree of change. If the impacts of technology are time-dependent, as we suspect they are, researchers need to attempt to build time explicitly into their studies. We recognize that longitudinal investigations are not always feasible. However, in cross-sectional studies researchers can identify the timing of their observations and perhaps compare the timing across sites to make statements about effects of the stage of implementation.

(4) Theoretical formulations should focus more on PMT's influence on interrelationships among variables rather than the variables themselves. We believe that a focus on interrelationships amounts to a focus on congruencies or matches. For example, in studying the impact of PMT, matches between job needs and skills of individuals might be examined. In other words, we are suggesting that one not simply examine the skill, but rather the match between skills and job requirements. In the current work of the second author, areas of matches being pursued include:

- between organizational goals and work objectives;

- between organizational goals/work objectives and technology system design decisions; 
- between human infrastructure design decisions made for each job (e.g., task specialization, reward system, performance measurement system, skills, discretion, coordination, etc.);

- between human infrastructure design decisions and technology system design decisions;

- between human infrastructure design decisions made across multiple levels of the organization; and

- between human infrastructure design decisions and organizational goals/work objectives.

(5) Research needs to be conducted on the relative importance weightings of the various design and process features. Advocates of organizational change tend to argue that the process features are far more important than the design features for successful organizational change, i.e., even a good organizationaltechnology design can fail to achieve its goals if implemented incorrectly and, inversely, even a bad (i.e., incongruent) organizational-technology design can achieve benefits if implemented correctly. While it is probably hard to argue with the proposition that bad implementation leads to poor success, it is far more equivocal to say that bad implementation of a good design is worse than good implementation of a bad design or maintaining a known bad design. More evidence on the relative weights of design and process features is needed so we arrive at a short list of critical characteristics that effect the change process.

We believe that the complexity of the study of the social impacts of technology justifies an eclectic set of research paradigms and strategies. This field can benefit from both small-sample, in-depth studies that focus on a small number of organizations followed intensively over time, as well as more macrolevel studies that follow a larger number of organizations at a more abstract level. Cross-national research, though challenging because of the great numbers of variables that distinguish nations, offers the opportunity to look at the impact of technology under widely varying social, cultural, and economic conditions. Even the single case study can offer insights if the researcher approaches it with a rich theoretical perspective that considers contextual influences, recognizes the complexities of social process, and generates novel hypotheses for further testing. We will have to continue to learn what we can from the best of studies that use a variety of research methods and take a variety of theoretical perspectives.

\section{Acknowledgements}

The work described here was made possible in part by a research grant to the second author from the National Center for Manufacturing Sciences, GM, TI, and DEC. We would like to thank Phil Anderson for his careful reading 
and thoughtful commentary on the paper, which led to great improvements. We would also like to thank members of the Invisible College of Organizational Studies seminar at U.M. for their useful feedback.

\section{References}

Adler, P., 1986. New technologies, new skills. Calif. Manage. Rev., 29(1): 9-28.

Adler, P.S. and Helleloid, D.A., 1987. Effective implementation of integrated CAD/CAM: A Model. IEEE Trans. Eng. Manage., 34 (2): 101-107.

Adler, P. and Howard, R., 1990. Technology and the Future of Work. Highlights of the Seminar held at Stanford University, March 28 and 29, Stanford University, California.

Baldry, C. and Connolly, A., 1986. Drawing the line: Computer-aided design and the organization of the drawing office. New Technol. Work Employment, 1: 59-66.

Barley, S.R., 1986. Technology as an occasion for structuring: Evidence from observations of CT scanners and the social order of radiology departments. Admin. Sci. Q., 31: 78-108.

Burns, T. and Stalker, G., 1961. The Management of Innovation. Tavistock, London.

Bridges, W., 1991. Managing Transitions: Making the Most of Change. Addison-Wesley, Reading, MA.

Cooley, M.J.E., 1981. Some social implications of CAD. In: J. Mermet (Ed.), CAD in Medium Sized and Small Industries. North-Holland, Amsterdam, pp. 97-116.

Corbett, J.M., 1985. Prospective work design of a human-centered CNC lathe. Behav. Inf. Technol., 4(3): 201-214.

Crowston, K. and Malone, T.W., 1988. Information technology and work organization. In: M. Helander (Ed.), Handbook of Human-Computer Interaction. Elsevier, Amsterdam.

Dean, J.W. and Snell, S.A., 1991. Integrated manufacturing and job design: Moderating effects of organizational inertia. Acad. Manage. J., 34 (4): 776-804.

Emery, F.E. and Trist, E.L., 1965. The causal texture of organizational environments. Hum. Relat., 18: 21-32.

Emery, F. and Trist, E., 1978. Analytical model for sociotechnical systems. In: W. Pasmore and J. Sherwood (Eds.), Sociolechnical Syslems: A Sourcebook. University Associates, San Diego, CA.

Giddens, A., 1979. Central Problems in Social Theory. The University of California Press, Berkeley, CA.

Gill, C., 1985. Work, Unemployment, and the New Technology. Blackwell, Oxford.

Hackman, J.R. and Oldham, G.R., 1980. Work Redesign. Addison-Wesley, Reading, MA.

Hull, F.M. and Cullins, P., 1987. High-technology batch production systems: Woodwards missing type. Acad. Manage. J., 30(4): 786-797.

Kling, R. and Scacchi, W., 1982. The web of computing: Computer technology and social organization. In: M. Yovits (Ed.), Advances in Computing, Vol. 21. Academic Press, 1982.

Knight, K.A., 1985. Socio-technical engineering: An approach to technology integration. Paper presented at the Society of Manufacturing Engineering Autofact Conference, Detroit, MI, November.

Leonard-Barton, D. and Sinha, D.K., 1991. Mutual adaptation as a predictor of success in internal technology transfer. Paper presented at the August 1992 Academy of Management Meetings, Miami, FL.

Majchrzak, A., 1988. The Human Side of Factory Automation. Jossey-Bass San Francisco, CA.

Majchrzak, A., 1991. Management of technological and organizational change. In: G. Salvendy (Ed.), Handbook of Industrial Enginecring. Wiley, New York, 2nd edn. 
Majchrzak, A. and Salzman, H., 1989. Social and organizational dimensions of computer-aided design. IEEE Trans. Eng. Manage., 36: 174-179.

Manufacturing Studies Board, 1986. Human Resource Practices for Implementing Advanced Manufacturing Technology. Committee of the Effective Implementation of Advanced Manufacturing Technology, National Academy Press, Washington, DC.

Markus, M. and Robey, D., 1988. Information technology and organizational change: Causal structure in theory and research. Manage. Sci., 34 (5): 583-587.

Nadler, D. and Tushman, M., 1980. A congruence model for diagnosing organizational behavior. In: I. Rubin and J. McIntyre (Eds.), Organizational Psychology. Prentice-Hall, Englewood Cliffs, NJ.

National Research Council, 1991. Research on the Management of Technology: Unleashing the Hidden Competitive Advantage. National Academy Press, Washington, DC.

Office of Technology Assessment, 1984. Computerized Manufacturing Automation. Library of Congress \#84-601053, Government Printing Office, Washington, DC.

Pasmore, W.A., 1988. Designing Effective Organizalions: The Socivtechnical Systems Perspective. Wiley, New York.

Perrow, C., 1967. A framework for the comparative analysis of organizations. Am. Sociol. Rev., 32: 194-208.

Rogers, E.M., 1983. Diffusion of Innovation. Free Press, New York, 3rd edn.

Salipante, P., Notz, W. and Bigelow, J., 1982. A matrix approach to literature reviews. In: Reseurch in Organizutiunal Behuvivo, Vul. 4. Jai Press, CT, pp. 321-348.

Shaiken, H., 1985. Work Transformed: Automation and Labor in the Computer Age, Holt, Rinehart and Winston, New York.

Taylor, J.C. and Asadorian, R.A., 1985. The implementation of excellence: STS management. Ind. Manage., (July-August): 5-15.

Thomas, R.J., 1993. What Machines Can't Do: Politics and Technology in the Industrial Enterprise. University of California Press, in press.

Walton, R.E. and Susman, G.I., 1987. People policies for the new machines. Harv. Bus. Rev., (March-April): 98-106.

Weick, K.E., 1990. Technology as equivoque: Sensemaking and new technologies. In: P.S. Goodman, (L.S. Sproull, and Associates (Eds.), Technology and Organizations. Jossey-Bass, San Francisco, CA.

Woodward, J., 1965. Industrial Organization: Theory and Practice. Oxford University Press, London.

\section{Appendix-Studies included in meta-analysis}

Adler, P.S., 1990. The skill requirements of CAD/CAM: An exploratory study. Int. J. Technol. Manage., 5: 201-216.

Adler, P.S., 1991. Workers assessments of three flexible manufacturing systems. Int. J. Hum. Factors Manuf., 1(1): 33-54.

Aronsson, G., 1989. Changed qualification demands in computer-mediated work. Appl. Psychol., 38: $57-71$.

Cummings, T. and Blumberg, M., 1987. Work design and manufacturing technology. In: T. Wall et al. (Eds. ), Human Implications of New Manufacturing Technology. Wiley, Chichester, UK.

De Pietro, R. and Schremser, G., 1987. The introduction of advanced manufacturing technology and its impact on skilled workers' perceptions of communication, interaction, and other job outcomes at a large manufacturing plant. IEEE Trans. Eng. Manage., 34(1): 4-11.

Edwards, J., 1988. Stress, coping, and worker well-being in computer-aided manufacturing: A field investigation of a CNC machine shop. In: W. Karwowski, H.R. Parsei and M.R. Wilhelm 
(Eds.), Ergonomics of Hybrid Automated Systems I. (Proc. 1st Int. Conf. on Ergonomics of Advanced Manufacturing and Hybrid Automated Systems, Louisville, KY). Elsevier, Amsterdam, pp. 101-108.

Ettlie, J.E., 1988. Taking Charge of Manufacturing. Jossey Bass, San Francisco, CA.

Gebbert, V., 1986. Group work and workstation-related workers' participation as modernization strategy in times of crisis. In: Skilled Based Automated Manufacturing. International Federation of Automatic Control Workshop, September, pp. 83-87.

Gerwin, D. and Tarondou, J., 1986. Consequences of programmable automation for French and American automobile factories: An international study. In: B. Lev (Ed.), Production Management: Methods and Studies. North-Holland, Amsterdam.

Gheissari, A. and Fiegener, M., 1989. The impact of computerized manufacturing technology on workers' perceptions of job satisfaction. ORSA/TIMS Cunf., May.

Goodman, P.S. and Miller, S., 1990. Designing effective vendor/user training through the technological life cycle. Natl. Productivity Rev., 9(2) (Spring): 169-178.

Jaikumar, R., 1986. Post-industrial manufacturing. Harv. Bus. Rev., 6: 69-76.

Johansson, G., 1989. Stress, autonomy, and the maintenance of of skill in supervisory control of automated systems. Appl. Psychol, 38: 45-56.

Jones, B. and Scott, P., 1986. Flexible manufacturing systems in Britain and the USA. New Technol. Work Employment, 1: 27-36.

Kelley, M.R., 1986. Programmable automation and the skill question: A reinterpretation of the cross-national evidence. IIum. Syst. Manage, 6: 223-241.

Kemp, N.J. and Clegg, C.W., 1987. Information technology and job design: A case study on computerized numerically controlled machine tool working. Behav. Inf. Technol, 6: 109-124.

Kemp, N. and Mueller, W., 1986. Advanced manufacturing technology and work simplification: An empirical study. J. Occupat. Behav., 8: 233-250.

Kidd, P.T., 1988. The social shaping of technology: The case of a CNC lathe. Behav. Inf. Technol, 7 (2): 193-204.

Kohler, E., 1986. Technological development, work organization, and employees in automated manufacturing. In: Skilled Based Automated Manufacturing. International Federation of Automatic Control Workshop, September, pp. 103-107.

Levi, D. and Slem, C., 1992. The human impact of technological change: A study of the attitudes and beliefs of employees of manufacturing companies. Int. J. Comput.-Integr. Manuf., in press.

Liker, J.K., Roitman, D.B. and Roskies, E., 1987. Changing everything all at once: Worklife and technological change. Sloan Manage. Rev., (Summer): 29-47.

Martensson, L., 1986. FMS-Flexibility for man and system. Skilled Based Automated Manufacturing, International Federation of Automatic Control Workshop, Scptember, 12326.

Meredith, J.R. and Green, S.G., 1987. A reexamination of organizational and behavioral changes in the factory of the future. Paper No. MATI-87W-001, Graduate Center for the Management of Advanced Technology and Innovation, College of Business $\Lambda$ dministration, University of Cincinnati, $\mathrm{OH}$.

Miller, S.M. and Bereiter, S.R., 1987. Impact of automation on process control decision-making. Robot. Comput. Integr. Manuf., 3: 311317.

Petro, J., 1983. Management of computer-aided drafting technology: Variables that affect system performance. Unpublished paper, Management Research seminar, Fairleigh Dickinson University, Madison, NJ.

Schumann, M., 1988. New workers' profiles in industry. Joint Design of Technology, Organization and People Growth Int. Conf., Venice, Italy.

Slem, C.M. and Levi, D.J., 1988. Assessing the impact of technology: Stress and its sources. California Polytechnic Institute, San Luis Obispo.

Stupp, H., 1987. The effects of CIM on work structures. Behav. Inf. Technol, 6: 291-298.

Wall, T.D., Clegg, C.W., Davies, R., Kemp, N.J. and Mueller, W.S., 1987. Advanced manufacturing technology and work simplification: An empirical study. J. Occupat. Behav., 8: 233-250.

Walton, R.E. and Susman, G.I., 1987. People policies for the new machines. Harv. Bus. Rev., March-April: 98-106. 